\title{
Clinical Analysis of Ectopic Pregnancy in a Tertiary Care Hospitals
}

\author{
Shazia Rani, Pushpa Goswami, Farhana Rajpar, Shazia Awan, Fahmida Gul
}

\begin{abstract}
OBJECTIVE: To determine Clinical presentation and risk factors of Ectopic pregnancy to highlight and drawing attention for early diagnosis and prompt management.

METHODOLOGY: This retrospective study was conducted in Department of Gynecology and Obstetrics at Liaquat University Hospital Hyderabad from January 2018 to December 2018. During one year of study period, 25 cases of ectopic pregnancies were enrolled in the study. In all cases age, parity, gestational age, risk factors, signs and symptoms, site of ectopic pregnancy and surgical intervention were noted on Performa and data was analyzed, results depicted in charts and tables.

RESULTS: Most patients aged between 20-30 years with gestational age of 2 months, in parity 08 were primigravida, 06 were gravida 1, 05 were gravida 2, 03 in each gravida 3 and 4 . One patient had a history of miscarriage, 02 underwent infertility treatment, 03 had previous ectopic pregnancy, 02 patients with previous cesarean section, while 08 patients given the history of pelvic inflammatory diseases. Six patients were diagnosed clinically while 15 cases through abdominal ultrasound and 4 through transvaginal ultrasound. Amenorrhea was present in 22 patients, vaginal bleeding in 20 cases and lower abdominal pain in 18 cases, while 08 patients presented in shock.

CONCLUSION: Early diagnosis prevents complications such as rupture of ectopic pregnancy, which end up with excision of fallopian tube or ovary badly affecting fertility.
\end{abstract}

KEYWORDS: Ectopic pregnancy, Cervical excitation, Clinical Analysis, TVS

This article may be cited as: Rani S, Goswami P, Rajpar F, Awan S, Gul F. Clinical Analysis of Ectopic Pregnancy in a Tertiary Care Hospitals. J Liaquat Uni Med Health Sci. 2019;18 (04):266-71. doi: 10.22442/jlumhs.191840640

\section{INTRODUCTION}

Ectopic pregnancy $(E P)$ is a worldwide problem with increasing frequency since last three decades, which accounts for approximately 1:100 of all pregnancies. In Pakistan the reported incidence is about 1:112 to $1: 130$. EP is a life and fertility threatening condition, foremost cause of maternal mortality during first trimester of pregnancy ${ }^{1}$.

A pregnancy is said to be ectopic when embryo implants at any other site rather than body of uterus or defined as an extra uterine gestational sac with yolk sac and/or embryo, with or without cardiac activity on transvaginal sonography (TVS). In $95 \%$ of cases it is seen in the fallopian tubes, classified as tubal and remaining $5 \%$ may occur in the cervix, ovaries or abdomen classified as non-tubal. Pelvic infection, smoking, previous pelvic surgery, infertility treatment are common risk factors. Anatomical or physiological blockage, decreased motility and dysfunctional cilia of fallopian tube probably promote implantation in tube. The certain mechanism is still unidentified which offers researchers to focus on understanding the etiology, preventable measure and develop new methods for early diagnosis and treatment of EP for better outcomes ${ }^{2-4}$.
Early diagnosis of EP is crucial step to determine the consequences from presentation to prognosis. The spectrum of presentations ranges from the asymptomatic woman diagnosed on transvaginal ultrasound (TVS) to massive intra-abdominal bleeding and shock. The classic symptoms of EP are triad of secondary amenorrhea, abdominal pain and vaginal bleeding, which is less frequently observed. Diagnostic criteria are based on serum beta-HCG concentration, transvaginal or abdominal ultrasound ${ }^{5,6}$.

EPs are potentially life threatening because as the fetus grows, beyond the capacity of tube, the tube ruptures leading to intraperitoneal bleeding. In developing countries, including Pakistan diagnosis and interventions are delayed versus early diagnosis in developed countries which favors good outcomes when compared with developing ones.

EPs often present as critical emergency with symptoms misleading to diagnosis, hence this study was intended to ascertain presentation; risk factor and management in our set up, to high light and add to local literature for drawing attention for early diagnosis and prompt management to reduce morbidity and mortality in tertiary care teaching hospital. 


\section{METHODOLOGY}

This retrospective study was conducted in Department of Gynecology and Obstetrics at Liaquat University Hospital Hyderabad from January 2018 to December 2018. After ethical approval and consent taken from patients lattendants of the patients, samples were collected by non probability convenient sampling. This study was carried out on all women diagnosed with ectopic pregnancy (EPs) admitted during study period and were included in this study, while patients in whom diagnosis of ectopic pregnancy was not confirmed or not willing were excluded from this study. A predesigned Performa was used to collect the data. The data was analyzed on SPSS software version 22 with simple descriptive statistics using percentages and depicted in charts and tables ${ }^{7}$.

\section{RESULTS}

During study period, 25 cases of Ectopic pregnancy were attended in the Department of Obstetrics and Gynecology, Liaquat University Hospital. Out of 25 women $22(88 \%)$ were aged between $20-30$ years, while $03(12 \%)$ were aged between $30-40$ years. Regarding parity out of 25 women, $08(32 \%)$ were primigravida, 06(24\%) were gravida 1, 05(20\%) were gravida 2, 03(12\%) in each gravida 3 and 4. Gestational age was up to one month in $10(40 \%)$ cases, $13(52 \%)$ had gestational age of two months and $02(8 \%)$ were having gestational age of 03 months according to date of last menstrual period given by patient or report of ultrasound. Regarding risk factors $01(04 \%)$ patient had history of miscarriage, 02(08\%) had gone for infertility treatment, and $03(12 \%)$ had previous pregnancy ectopic pregnancy, previous cesarean section was seen in $02(08 \%)$ patients while $08(32 \%)$ patients were given the history of pelvic inflammatory disease. Out of total 25 cases $06(24 \%)$ were clinically diagnosed, $15(60 \%)$ cases through abdominal ultrasound and 04(16\%) through transvaginal ultrasound. Surgical intervention is required in all cases salpingectomy was performed in $21(84 \%)$ cases, oophorectomy in $03(12 \%)$ cases and in $01(04 \%)$ patient tubal ligation was performed Table I.

As far as symptoms, history of gestational amenorrhea was given by 22 patients, vaginal bleeding was in 20 cases and lower abdominal pain was present in 18 cases, while 08 patients presented in shock, on examination abdominal tenderness was seen in 18 cases and cervical excitation was positive only in 05 patients Table II.

Regarding site of EPs commonest seen in tube in 22 (10 on right and 12 on left) cases and 03(02 in right and 01 in left) cases seen in ovary Table III.
TABLE I: DEMOGRAPHIC DATA OF PATIENTS WITH ECTOPIC PREGNANCY

\begin{tabular}{|c|c|c|}
\hline Age in years & $\begin{array}{c}\text { No. of } \\
\text { Patients }\end{array}$ & Percentage \\
\hline $20-30$ & 22 & $88 \%$ \\
\hline $31-40$ & 03 & $12 \%$ \\
\hline \multicolumn{3}{|l|}{ Parity } \\
\hline 0 & 08 & $32 \%$ \\
\hline 1 & 06 & $24 \%$ \\
\hline 2 & 05 & $20 \%$ \\
\hline 3 & 03 & $12 \%$ \\
\hline 4 & 03 & $12 \%$ \\
\hline \multicolumn{3}{|l|}{ Gestational age in months } \\
\hline 01 & 10 & $40 \%$ \\
\hline 02 & 13 & $52 \%$ \\
\hline 03 & 02 & $08 \%$ \\
\hline \multicolumn{3}{|l|}{ Risk Factors } \\
\hline Previous Miscarriage & 01 & $04 \%$ \\
\hline Infertility Treatment & 02 & $08 \%$ \\
\hline previous Ectopic pregnancy & 03 & $12 \%$ \\
\hline Previous Cesarean Section & 02 & $08 \%$ \\
\hline Pelvic Inflammatory Disease & 08 & $32 \%$ \\
\hline \multicolumn{3}{|l|}{ Diagnostic Tool } \\
\hline Clinical & 06 & $24 \%$ \\
\hline Ultrasound pelvis & 15 & $60 \%$ \\
\hline Transvaginal ultrasound & 04 & $16 \%$ \\
\hline \multicolumn{3}{|l|}{ Surgical Intervention } \\
\hline Salpingectomy & 21 & $84 \%$ \\
\hline Oophorectomy & 03 & $12 \%$ \\
\hline Tubal ligation & 01 & $04 \%$ \\
\hline
\end{tabular}

TABLE II: SHOWING SYMPTOMS AND SIGNS OF ECTOPIC PREGNANCY

\begin{tabular}{|l|c|l|c|}
\hline Symptoms & $\begin{array}{c}\text { No. of } \\
\text { Patients }\end{array}$ & \multicolumn{1}{|c|}{ Signs } & $\begin{array}{c}\text { No. of } \\
\text { patients }\end{array}$ \\
\hline Amenorrhea & $22(88 \%)$ & $\begin{array}{l}\text { Syncopel } \\
\text { shock }\end{array}$ & $08(32 \%)$ \\
\hline $\begin{array}{l}\text { Vaginal } \\
\text { Bleeding }\end{array}$ & $20(80 \%)$ & $\begin{array}{l}\text { Abdominal } \\
\text { tenderness }\end{array}$ & $18(72 \%)$ \\
\hline $\begin{array}{l}\text { Abdominal } \\
\text { Pain }\end{array}$ & $18(72 \%)$ & $\begin{array}{l}\text { Cervical exci- } \\
\text { tation +ve }\end{array}$ & $05(20 \%)$ \\
\hline
\end{tabular}


Shazia Rani, Pushpa Goswami, Farhana Rajpar, Shazia Awan, Fahmida Gul

TABLE III:

SHOWING SITE OF ECTOPIC PREGNANCY

\begin{tabular}{|c|c|c|c|}
\hline \multicolumn{4}{|c|}{ Site: Fallopian tube } \\
\hline \multicolumn{2}{|c|}{ Right } & \multicolumn{2}{|c|}{ Left } \\
\hline Rupture & Un ruptured & Rupture & Un ruptured \\
\hline $09(36 \%)$ & $01(04 \%)$ & $10(40 \%)$ & $02(08 \%)$ \\
\hline \multicolumn{4}{|c|}{ Ovary } \\
\hline \multicolumn{2}{|c|}{ Right } & \multicolumn{2}{|r|}{ Left } \\
\hline Rupture & Un ruptured & Rupture & Un ruptured \\
\hline 01 (04\%) & 01 (04\%) & $00(00 \%)$ & $01(04 \%)$ \\
\hline
\end{tabular}

\section{DISCUSSION}

EP is a clinical manifestation of poor fertility, accounting for $1 \%$ to $2 \%$ of all pregnancies carries significant risk factor for future fertility with poor outcomes in successive pregnancies. Patient may present with irrelevant symptoms such as shock without awareness of pregnancy which is misleading situation for diagnosis and management. Hormonal levels of $\beta$-human chorionic gonadotropin ( $\beta$-hCG) and abdominal or transvaginal ultrasound are mainstay of diagnosis ${ }^{8}$.

In this study majority of patients were aged between 20 - 30 year i.e. $22(88 \%)$ out of 25 which are similar to the studies conducted by Shabab $U 2013^{9}$ and Poonam Y $2005^{10}$, this relevance is also correlated with the peak reproductive age as well.

Studies regarding parity showed more frequency in primiparous by Islam A et al $(31.3 \%)^{11}$, at Ayub hospital as seen in this study also, where out of 25 women $08(32 \%)$ were primigravida, while Shafquat T $2013^{12}$ found most frequent among multipara (47.3\%) as compared to primipara $(34.66 \%)$. In this study 06 $(24 \%)$ were gravida $1,05(20 \%)$ were gravida 2,03 $(12 \%)$ each in gravida 3 and 4 which is almost similar to other authors.

Tahmina S $2016^{13}$ and Khaleeque F $2001^{14}$ studied gestational age of 6-7 weeks, similar presentation was found in this study as well where gestational age of one month seen in $10(40 \%)$ cases, $13(52 \%)$ had gestational age of two months and $02(08 \%)$ were having gestational age of 03 months.

In our study $16(64 \%)$ out of 25 cases of ectopic pregnancy risk factors are identified which are comparable with other studies as well. Risk factors identified in this study are as $01(04 \%)$ patient had history of miscarriage ${ }^{15}$, while Shrivastiva M $2017^{16}$ observed miscarriage in $17 \%$ and $34 \%$ by Tahmina S $2016^{13}$.

Infertility treatment was reported by $02(08 \%)$ patients, which corresponds with Bhavina et $\mathrm{al}^{17}$ who noticed ovulation induction in $10 \%$ cases and similar by Khaleeque $\mathrm{F} 2001^{14}$ as well.

We observed $03(12 \%)$ patients had previous pregnancy ectopic, and $02(08 \%)$ had previous cesarean section, while Islam $\mathrm{A}$ et $\mathrm{al}^{11}$ found previous ectopic in $4.44 \%$ and previous abdominal pelvic surgery in $6.67 \%$ of cases, Priyadarshini B et $\mathrm{al}^{18}$ found Caesarean section in $13 \%$ patients and previous ectopic in $9 \%$ patients which are closer to our study. Most common identified risk factor was pelvic inflammatory disease seen in $08(32 \%)$ patients which were reported similar by Bhavana et $\mathrm{al}^{17} 22.70 \%$ and Hassan N 20097 $35.4 \%$.

As the diagnosis of EP in earlier stage provide the opportunity of availing conservative treatment and minimizing risk for patient life and fertility. TVS is of gold standard value in diagnosis of EP in early first trimester, by notifying more than $80 \%$ of EPs before rupture and more than $50 \%$ in asymptomatic women. As most of the patients referred to tertiary care hospitals are from rural areas which are deprived of basic health care facilities, patients due to unawareness and poverty frequently not assess the basic health facilities even if present. Usually patients of EP are brought in emergency without any investigation regarding pregnancy and in such situation clinical presentation are correlated with history and diagnosis was ensured by ultrasound and hormonal assay of beta $\mathrm{HCG}^{19}$.

In this study out of total 25 cases 06 (24\%) were clinically diagnosed, $15(60 \%)$ cases through abdominal ultrasound and 04(16\%) through transvaginal ultrasound whereas lqbal $A$ et al $^{11}$ found (51.11\%) were clinically diagnosed, 20(44.44\%) through abdominal ultrasound and $2(4.44 \%)$ through vaginal ultrasound. Although there is difference in clinical diagnosis in both studies but regarding abdominal ultrasound similar results are found probably due to lack of facility of transvaginal sonography. Study conducted by Khan B $2013^{20}$ shows diagnosis on clinical assessment more than other parameters. 
As most patients present with ruptured tubal pregnancy surgical intervention is required in emergency and for securing massive bleeding usually laparotomy with salpingectomy is performed which definitely reducing the fertility of woman to $50 \%$, therefore it's the classical need of time to create awareness among ladies of reproductive age especially with risk factors must have transvaginal scan to confirm pregnancy moreover the site of pregnancy which may be helpful if diagnosed earlier in conserving fertility by treating ectopic with medical therapy. However, in our study as in many developing countries, salpingectomy was done due to late presentation in $21(84 \%)$ cases, oophorectomy in 03 $(12 \%)$ cases and in $01(04 \%)$ patient tubal ligation was also performed with salpingectomy similar are reported by Tahmina $S 2016^{13}$ and lgwegbe AO $2013^{21}$ who conducted study in the developing setup similar to us.

Regarding symptoms history of amenorrhea is given by $22(88 \%)$ patients, vaginal bleeding was in $20(80 \%)$ cases and lower abdominal pain was present in 18 $(72 \%)$ cases, this classical triad of symptoms was seen in $70 \%$ of our cases. Singh S $2014^{22}$ reported this triad to be present in $28-95 \%$ women. History of amenorrhea and vaginal bleeding were found in $(73.6 \%)$ and $(57.8 \%)$ patients as reported by Shah $\mathrm{N}$ $2005^{23}$, while Qazi Q $2010^{24}$ reported abdominal pain $(90 \%)$, amenorrhea $(84 \%)$, vaginal bleeding $(70 \%)$, both studies almost resembles with present study.

Abdominal and cervical motion tenderness is classical signs of an EP which are unfortunately not seen in most patients. Here also 08(32\%) patients present in shock, on examination abdominal tenderness was seen in $18(72 \%)$ cases and cervical excitation was positive only in $05(20 \%)$ patients shown in Table II. Khaleeque $\mathrm{F} 2001^{14}$ reported abdominal tenderness in $84.6 \%$ and cervical excitation in $64 \%$, Patel M $2016^{25}$ reported cervical excitation in $48 \%$ of cases, while Ehsan N $1998^{26}$ reported shock in $24 \%$ abdominal tenderness in $80 \%$ and cervical excitation in $90 \%$ variation is possible due to presentation of patients in variable age of gestation as well as varying preconception status of every patient.

Regarding site of EPs commonest seen in tube in 22 $(88 \%), 10(40 \%)$ on right and $12(48 \%)$ on left) tube, and in ovary $03(12 \%)$ of which $(02(08 \%)$ in right and $01(04 \%)$ in left) ovary shown in Table III. Shrivastava $\mathrm{M}$ and Parashar $\mathrm{H} 2017^{16}$ found $90 \%$ in Fallopian tube, $04 \%$ in ovary and remaining adherent to bowel or heterotopic which is not seen in present study out of which ruptured ectopic in $91.5 \%$ cases while in $9 \%$ unruptured tube was observed. Study by Islam $A$ et $\mathrm{al}^{11}$ reported $71.1 \%$ patients with ruptured ectopic while $28.9 \%$ were present with unruptured ectopic with evidence of $62.2 \%$ cases in right sided fallopian tube and $37.8 \%$ were in left sided fallopian tube. These findings regarding site are not in agreement with study by Islam A et $\mathrm{al}^{11}$ and Musa $\mathrm{J} 2009^{27}$ who found most cases in right while study by Poonam $Y 2005^{10}$ shows no significant difference in site.

\section{CONCLUSION}

Ectopic pregnancy is dire obstetrical emergency in women of reproductive age. This critical situation can be handled by prompt diagnosis through TVS, urgent referral to tertiary health care and taking required interventions (laparotomy, laparoscopy) to conserve fertility and fatality. Awareness must be given to females of child bearing age through electronic/social media forums as to seek immediate medical care/ advice if there are symptoms of syncope and lower abdominal pain with missing of menstrual cycle even of shorter duration to rule out ectopic pregnancy.

\section{ACKNOWLEDGEMENT}

We are grateful to the Prof. Dr. Raheel Sikander, Head of Gynecology \& Obstetrics Department, LUH Hyderabad, for facilitating us to collect data.

Ethical permission: Department of Obstetrics \& Gynaecology, Liaquat University of Medical \& Health Sciences Jamshoro letter No. LUMHS/Chairperson OBGYN/-062/19 Dated: 03-10-2019.

Conflict of interest: Authors of the study have no conflict of interest to declare.

Funding: There was no any funding agency.

\section{REFERENCES}

1. Brady PC. New Evidence to Guide Ectopic Pregnancy Diagnosis and Management. Obstet Gynecol Surv. 2017; 72(10): 618-25. doi: 10.1097/ OGX.0000000000000492.

2. Van Den Eeden SK, Shan J, Bruce C, Glasser M. Ectopic pregnancy rate and treatment utilization. Obstet Gynecol. 2005; 105(5 Pt 1): 1052-7.

3. Bhattacharya $S$, McLernon DJ, Lee AJ, Bhattacharya S. Reproductive Outcomes 
Following Ectopic Pregnancy: Register-Based Retrospective Cohort Study. PLoS Med. 2012; 9 (6): e1001243. doi: 10.1371/journal.pmed. 1001243.

4. Nadim B, Infante F, Lu C, Sathasivam N, Condous G. Morphological ultrasound types known as 'blob' and 'bagel' signs should be reclassified from suggesting probable to indicating definite tubal ectopic pregnancy. Ultrasound Obstet Gynecol. 2018; 51(4): 543-549. doi: 10.1002/uog. 17435 .

5. Marion LL, Meeks GR. Ectopic pregnancy: History, incidence, epidemiology, and risk factors. Clin Obstet Gynecol. 2012; 55(2): 376-86. doi:10.1097/GRF.0b013e3182516 d7b.

6. Chen X, Chen Z, Cao Z, Han K, Tong Y, Xiang X, et al. The 100 most cited articles in ectopic pregnancy: a bibliometric analysis SpringerPlus. 2016. 5: 1815. doi:10.1186/s40 064-016-3503-8.

7. Hassan N, Zaheen Z, Jatoi N, Srichand P, Shaikh F. Risk factors, Clinical presentations and Management of 62 Cases of Ectopic Pregnancy at Tertiary Care Centre. J Liaquat Uni Med Health Sci. 2009; 8(3): 238-41.

8. Alkatout I, Honemeyer U, Strauss A, Tinelli A, Malvasi $A$, Jonat $W$, et al. Clinical diagnosis and treatment of ectopic pregnancy. Obstet Gynecol Surv. 2013; 68(8): 571-81. doi: 10.1097/OGX. 0b013e31829cdbeb.

9. Shabab U, Hashmi HA. Different pattern of presentation of ectopic pregnancy and its management. J Surg Pak. 2013; 18(1): 37-40.

10. Poonam Y, Uprety D, Banerjee B. Ectopic Pregnancy - two years review from BPKIHS, Nepal. Kathmandu Uni Med J. 2005; 3(4): 365-9.

11. Islam A, Fawad A, Shah AA, Jadoon H, Sarwar I, Abbasi AU. Analysis of two years cases of ectopic pregnancy. J Ayub Med Coll Abbottabad. 2017; 29(1): 65-67.

12. Shafquat T, Wahab $S$, Bawar $S$, Rahim R. Relation of age, parity, and duration of subfertility as risk factors for ectopic pregnancy. Gomal J Med Sci. 2013; 11(2): 171-3.

13. Tahmina S, Daniel M, Solomon P. Clinical Analysis of Ectopic Pregnancies in a Tertiary Care Centre in Southern India: A Six-Year Retrospective Study. J Clin Diagn Res. 2016; 10 (10): QC13-QC16.

14. Khaleeque F, Siddiqui RI, Jafarey SN. Ectopic pregnancies: A three year study. J-Pak Med Assoc. 2001; 51(7):240-2.

15. Singh S, Mahendra G, Vijayalakshmi S, Pukale RS. Clinical study of ectopic pregnancy in a rural setup: A two year survey. Natl J Med Res. 2018; 4 (1): 37-9.

16. Shrivastava M, Parashar H, Modi JN. A clinical study of ectopic pregnancy in a tertiary care centre in central India. Int J Reprod Contracept Obstet Gynecol. 2017; 6(6): 2485-90. doi:10.18203/2320-1770.ijrcog20172336.

17. Bhavna , Gupta KB, Pathania K, Jindal M, Vohra R, Ahmed M. Risk Factors For Ectopic Pregnancy: A Case Control Study In Tertiary Care Centre. IOSR J Dent Med Sci. 2014; 13(3): 23-27. doi:10.9790/0853-13342327.

18. Priyadarshini $B$, Padmasri $R$, Jnaneshwari $T L$, Sowmya KP, Bhatara U, Hema V. Ectopic pregnancy: a cause for maternal morbidity. Int $\mathrm{J}$ Reprod Contracept Obstet Gynecol. 2016; 5 (3):700-704. doi:10.18203/2320-1770.ijrcog 20160569.

19. Kirk E, Papegeorghiou AT, Condous G, Tan L, Bora S, Bourne T. The diagnostic effectiveness of an initial transvaginal scan in detecting ectopic pregnancy. Hum Reprod. 2007; 22(11): 2824-8.

20. Khan B, Deeba F, Khan W. A 10 Year Review of 255 cases of Ectopic Pregnancy. J Androl Gynaecol. 2013; 1(2): 4.

21. Igwegbe AO, Eleje GU, Okpala BC. An appraisal of the management of ectopic pregnancy in a nigerian tertiary hospital. Ann Med Health Sci Res. 2013; 3(2): 166-70.

22. Singh S, Mahendra G, Vijayalakshmi S, Pukale RS. Clinical study of ectopic pregnancy in a rural setup: A two year survey. Natl J Med Res. 2014; 4 (1): 37-39.

23. Shah $\mathrm{N}$, Khan $\mathrm{NH}$. Ectopic pregnancy: presentation and risk factors. J Coll Physicians Surg Pak. 2005; 15(9): 535-8.

24. Qazi Q, Akhtar Z, Khan K. Clinical presentations and complications associated with tubal rupture in patients with tubal ectopic pregnancy. J Postgrad Med Inst 2010; 24(4): 312-7.

25. Patel M, Chavda D, Prajapati S. A retrospective study of 100 cases of ectopic pregnancy: clinical presentation, site of ectopic and diagnosis evaluation. Int J Reprod Contracept Obstet Gynecol. 2016; 5: 4313-6. doi:10.18203/2320- 
1770.ijrcog20164334.

26. Ehsan N, Mahmood A. Ectopic pregnancy: an analysis of 62 cases. J Pak Med Assoc. 1998; 48 (2): 26-9.
27. Musa J, Daru PH, Mutihir JT, Ujah IA. Ectopic pregnancy in Jos Northern Nigeria: prevalence and impact on subsequent fertility. Niger $\mathrm{J}$ Med. 2009; 18(1): 35-8.

\section{洸}

AUTHOR AFFILIATION:

Dr. Shazia Rani

Assistant Professor

Department of Obstetrics and Gynecology

Liaquat University Hospital

Jamshoro, Sindh-Pakistan.

Dr. Pushpa Goswami (Corresponding Author)

Associate Professor

Department of Anatomy

Liaquat University of Medical and Health Sciences

(LUMHS), Jamshoro, Sindh-Pakistan.

Email: pushparamesh1998@gmail.com

\section{Dr. Farhana Rajpar}

Assistant Professor

Department of Anatomy

LUMHS, Jamshoro, Sindh-Pakistan.

\section{Dr. Shazia Awan}

Assistant Professor

Department of Obstetrics and Gynecology

Liaquat University Hospital

Jamshoro, Sindh-Pakistan.

\section{Dr. Fahmida Gul}

Lecturer

Department of Anatomy

LUMHS, Jamshoro, Sindh-Pakistan. 